\title{
Etiological and Evolutionary Profile of the Child's Pericarditis in Tropical Environments
}

\author{
Richard Azagoh-Kouadio', Jacob Slanziahuelie Enoh1, Jean-Jacques Yao Atteby', \\ Line Guei Couitchéré1, Lassina Cisse1, Yves N'da Kouakou N'goran², Kouadio Euloge Kramoh², \\ Oulaï Soumahoro ${ }^{1}$
}

\footnotetext{
${ }^{1}$ Paediatric Ward of University and Teaching Hospital of Treichville, Abidjan, Cote d'Ivoire

${ }^{2}$ Institute of Cardiology of Abidjan (ICA), Abidjan, Cote d'Ivoire

Email: azagoh.richard@gmail.com, Jacobeno2006@yahoo.fr, attebyjj@yahoo.fr, coutlin2@voila.fr, cisselassi@hotmail.fr, ngoran.yves@gmail.com,krakoueul@yahoo.fr, oulsoum@yahoo.fr
}

How to cite this paper: Azagoh-Kouadio, R., Enoh, J.S., Yao Atteby, J.-J., Couitchéré, L.G., Cisse, L., N'goran, Y.N.K., Kramoh, K.E. and Soumahoro, O. (2017) Etiological and Evolutionary Profile of the Child's Pericarditis in Tropical Environments. Open Journal of Pediatrics, 7, 164-177.

https://doi.org/10.4236/ojped.2017.73020

Received: July 16, 2017

Accepted: August 26, 2017

Published: August 29, 2017

Copyright $\odot 2017$ by authors and Scientific Research Publishing Inc. This work is licensed under the Creative Commons Attribution International License (CC BY 4.0).

http://creativecommons.org/licenses/by/4.0/

\begin{abstract}
Background: Liquid pericarditis is a frequent cause of hospitalization in developing countries. Objective: of this study was to describe the etiological and evolutionary aspects of fluid pericarditis in pediatric cardiology at ICA. Methods: This was a retrospective study of 42 cases of fluid pericarditis diagnosed among 202 children hospitalized over a five-year period ( $1^{\text {st }}$ January 2009 to $31^{\text {st }}$ December 2014). All patients with pericardial effusion were included in the study. Results: Prevalence was estimated at $20.8 \%$ of hospitalizations, sex ratio was 1.1 with a female predominance (52\%) and the mean age at 9.2 years (11 days to 15 years). The etiologic varieties identified were: tuberculosis 22 cases, $52 \%$, rheumatic pericarditis 6 cases or $14.3 \%$, chronic parietal endocarditis 5 cases (11.9\%), bacterial pericarditis with trivial germ 3 cases $(7.1 \% 3$ cases $(7.1 \%)$, post-surgery syndrome 2 cases $(4.8 \%)$, umbilical post-catheterization 1 case (2.4\%). HIV serology was positive in $11.9 \%$ of cases. The progression was favorable in $55 \%$ of the cases with $10 \%$ of deaths. Conclusion: Fluid pericarditis in children is a severe condition that is clearly on the rise today, especially in immunocompromised patients. Optimal management of fluid pericarditis in children is the best guarantee to avoid short-term tamponade and in the medium term constriction.
\end{abstract}

\section{Keywords}

Pericarditis, Etiology, Evolution, Children, Tropical Diseases

\section{Introduction}

Liquid pericarditis, serious illness, is a frequent cause of hospitalization in cardi- 
ology, especially in developing countries.

However, its prevalence is undoubtedly underestimated. It would reach $1 \%$ according to autopsy series [1]. Etiological research remains difficult due to the weakness of the technical platform and/or lack of financial resources. Recent work has reassessed the main etiologies of pericarditis in the West [2]. In Africa, in the absence of an updated study, we report our experience of the etiological and evolutionary aspects of fluid pericarditis.

\section{Patients and Methods}

\subsection{Methods}

We reviewed the 202 cases of all the patients hospitalized in the pediatric cardiology department of the Institute of Cardiology of Abidjan (I.C.A) over a period of five years ( $1^{\text {st }}$ January 2009 to $31^{\text {st }}$ December 2014).

Among these cases, we noted 42 cases or $20.8 \%$ of fluid pericarditis on the following criteria:

\subsubsection{Inclusion Criteria}

\section{1) Complete medical file with:}

- Clinical arguments in favor of fluid pericarditis.

- Paraclinical arguments: cardiomegaly on thoracic radiography, microvoltage and Holzmann's repolarization problems with electrocardiography (ECG), liquid pericardial effusion at echocardiography and biological abnormalities.

- Favorable development under treatment according to etiology.

2) Mandatory hospitalization in the service for at least 15 days.

\subsubsection{Non-Inclusion Criteria}

- Incomplete medical records either due to poor clinical evidence and/or failure to perform paraclinical examinations (thoracic radiography, ECG, echocardiography and specific biology).

- Refusal of hospitalization for various reasons.

\subsection{Patients}

Based on these criteria, we selected 42 patients of 22 women (52\%) and 20 men (48\%), with an average age of 9.2 years (range 1 to 15 years).

\subsection{Analysis of the Results}

The data were obtained from medical records using a standardized survey form.

The parameters studied are clinical, paraclinic, etiological and evolutionary.

The data was collected under Excel 2003 and analyzed under SPSS 11.

\subsection{Therapeutic Protocol According to the Etiology at the Time of the Study}

The medical treatment was carried out in all cases according to the etiological diagnosis. Antituberculosis treatment included a 4 -fold combination for 2 
months (2RHZE) at an effective dose of: Isoniazid ( $5 \mathrm{mg} / \mathrm{kg} /$ day); Rifampicin (10 mg/kg/day); Etambutol (20 mg/kg/day); And Pyrazinamide (30 mg/kg/day). After two months, pyrazinamide and etmbutol were stopped. We continued for 4 months a dual therapy (4 $\mathrm{RH})$ combining Isoniazide and Rifampicin with usual liver and eye monitoring. The duration of treatment is 6 months or more.

We associate corticosteroids at $1-2 \mathrm{mg} / \mathrm{kg} /$ day -maximum $80 \mathrm{mg}$ for four weeks and then a gradual decrease was made with a stop in the $2^{\text {nd }}$ month if the exudative reaction was strong. In children under seven years of age or weighing less than $21 \mathrm{~kg}$, the protocol was $2 \mathrm{RHZ}$ and $4 \mathrm{RH}$ (contraindicated).

In case of AIDS, we observed pericarditis due to mycobacteria (Mycobacterium avium, Mycobacterium tuberculosis).

The treatment was opportunistic infections and associated with antiretroviral background therapy.

In the case of rheumatic pericarditis, penicillin was administered at a dose of 1 to 2 million units per 24 hours for 15 days followed by prophylactic treatment (benzathine-penicillin at 600,000 IU/IM every 15 days in children and $1.2 \mathrm{M}$ IU/IM in adolescents every 20 days for 5 years).

We combined corticosteroids at $1-2 \mathrm{mg} / \mathrm{kg} / \mathrm{d}$ (maximum $80 \mathrm{mg}$ ) for four weeks and then gradually decreased with a stop in the $2^{\text {nd }}$ month.

High-dose aspirin $100 \mathrm{mg} / \mathrm{kg} / 24 \mathrm{~h}$ was an alternative.

In the case of pericarditis with a common germ, the surgical drainage was performed and allowed to take bacteriological samples, a toilet of the pericardium and local instillations of antibiotic. The precocity and efficacy of the antibiotic treatment associated with preventive corticosteroid therapy of pericardial constriction was required for 10 to 15 days intravenously. The molecules used were a 3rd generation cephalosporin or amoxicillin + clavulanic acid 100 to 200 $\mathrm{mg} / \mathrm{kg} /$ day, an aminoglycoside $5 \mathrm{mg} / \mathrm{kg} /$ day and metronidazole $30 \mathrm{mg} / \mathrm{kg} /$ day.

In the case of neoplastic pericarditis, chemotherapy treatment was instituted in pediatric oncology following an evacuating puncture.

In the case of postoperative pericarditis (Post-surgery syndrome/Umbilical catheterization), the treatment required emergency surgical recovery for drainage.

\subsection{Ethical Rules}

The agreement of the head of department, the anonymity and the destruction of the fact sheets after their exploitation were respected and no conflict of interest was declared.

\section{Results}

\subsection{Clinical Aspects}

Dyspnea (64\%), cardiomegaly (24\%), fever (10\%) and chest pain $(48 \%)$ were dominated by the discovery.

Different stages of dyspnea were observed with a predominance of stage IV dyspnea (48.1\%) followed by stage III dyspnea (25.9\%) (Figure 1). 


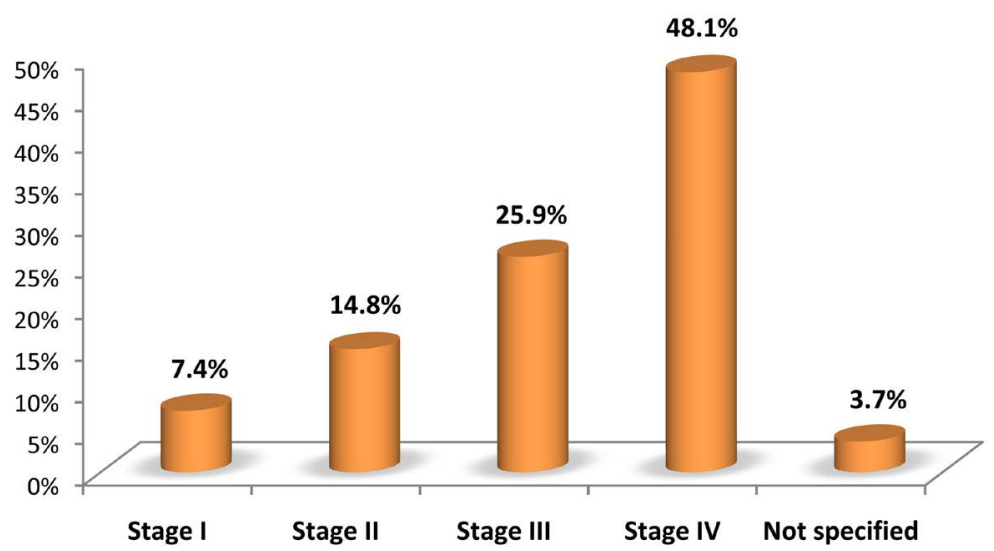

Figure 1. Distribution of the children according to the stage of dyspnea.

The clinical presentation of adiastolia was the most frequent (97\%). Tamponade was observed in $3 \%$ of cases.

\subsection{Paraclinical Aspects}

The most frequently seen radiological abnormality was cardiomegaly (100\%). The mean of the cardiothoracic index (I.C.T) was 0.71 with extremes ranging from 0.59 to 0.87 . We find that $55 \%$ of the patients had an I.C.T between 0.65 and 0.80 . We observed 10 cases (24\%) of pleurisy associated with pericarditis.

Electrolytically, we had decreases in repolarization (100\%), sinus tachycardia (97\%), microvoltage (85\%) and atrial fibrillation (9\%). The electrical signs of repolarization characteristic of pericarditis were dominated by stage III of Holtzmann (43\%), followed by stage II (38\%) and stage IV (19\%) (Table 1).

The echocardiogram confirms the diagnosis in all patients with $67 \%$ high pericarditis, $19 \%$ minimal pericarditis, and $14 \%$ moderate abundance pericarditis.

Pericardial puncture strongly oriented the diagnosis by the appearance of the liquid: citrin (64\%), serohematic (30\%) and purulent (6\%).

Treatment varied according to etiology. In addition, cardiac ultrasound was used to guide emergency treatment (puncture-evacuation).

An effusion drainage puncture was performed in 64\% of children and 14\% had drainage. Evacuating therapeutic abstinence was observed in 9 children. The average amount of liquid removed was 280 milliliters (50 to 1800 milliliters).

\subsection{Aetiological Varieties}

Our etiological investigation made it possible to link fluid pericarditis to a cause in all our patients.

Tuberculosis is the dominant etiology with 22 cases (52.4\%) followed by acute rheumatic fever (6 cases), $14.3 \%$ and 5 cases of pericarditis due to chronic parietal endocarditis. We have 3 cases of bacterial pericarditis, 3 cases of pericarditis of neoplastic origin, 2 Pericarditis in a post-surgery syndrome and 1 case of umbilical post-catheterization pericarditis (Table 2). 
Table 1. Distribution of the children according to the electrocardiographic anomalies.

\begin{tabular}{ccc}
\hline RESULTATS & FREQUENCY & PERCENTAGE (\%) \\
\hline DISTURB REPOARISATION & 42 & 100 \\
SINUSAL TACHYCARDIAL & 41 & 97 \\
PERIPHERIAL MICROVOLTAGE & 36 & 85 \\
HVD & 6 & 15 \\
HAD & 5 & 12 \\
AC/FA & 4 & 9 \\
STAGE 2 HOLTZMANN & 16 & 38 \\
STAGE 3 HOLTZMANN & 18 & 43 \\
STAGE 4 HOLTZMANN & 8 & 19 \\
\hline
\end{tabular}

Table 2. Distribution of the children according to the etiology of the pericarditis fluid.

\begin{tabular}{ccc}
\hline ETIOLOGIES & FREQUENCY & PERCENTAGE (\%) \\
\hline Tuberculous pericarditis & 22 & 52,4 \\
Rheumatic pericarditis & 06 & 14,3 \\
Chronic parietal endocarditis & 05 & 11,9 \\
Pericarditis with common germs & 03 & 7,1 \\
Neoplastic pericarditis & 03 & 7,1 \\
Postpericardotomy syndrome & 02 & 4,8 \\
Umbilical Postcatheterisme & 01 & 2,4 \\
\hline
\end{tabular}

HIV serology was prescribed and performed in 33 children (78.6\%) after obtaining, after an interview, the consent of the parents. Retroviral serology was positive in 5 cases $(11.9 \%)$. All HIV positive patients had tuberculosis. The serological test was negative in 28 children (66.7\%). On the other hand, we were unable to carry out this examination in 9 patients because of the parents' refusal. The population of HIV-positive patients had an average age of 3 years ( 2 years to 5 years).

\subsection{Evolution and Complications}

The vast majority (64\%) of our patients received an evacuating pericardial puncture. Pericardial drainage was performed in 6 children of this cohort. Nine patients did not receive either drainage or drainage as there was minimal effusion in eight of them and one of the children with moderate pericarditis did not have the means to achieve puncture.

There were 4 deaths (10\%). Healing was achieved in 23 patients (55\%) with a 1-year follow-up. In our series, we found 8 patients lost to follow-up (19\%). In 7 patients (16\%), a constrictive pericarditis was formed.

\section{Discussion}

Our study aimed to describe the etiologies of fluid pericarditis in the child pop- 
ulation in a tropical country with precarious health conditions and to assess their future. This population can be regarded as representative because of the completeness of the census over the five years.

We found a prevalence (20.8\%) higher than that of MALU et al. (12\%) in Congo-Kinshasa [3] and below that of Niakara (51\%) in Burkina [4]. The presence of pericardial effusion is described with a prevalence of 5 to $30 \%$ of HIV-infected patients, according to series [5] [6], but it is in more than $80 \%$ of asymptomatic cases. Our prevalence is certainly below reality, because a non-negligible share of asymptomatic pericarditis [7], as well as more precise diagnostic methods, would give a higher prevalence [8].

The mean age was 9.2 years (11 days to 15 years). Similar data are observed in the Tunisian series of Benchekroun T.S. et al. [9] with an average age of 7 years (8 months to 14 years) and in the Moroccan series of F. Hmami et al. (6 years) [10]. Our results differ from those of By Omer Cakir et al. [11] in Turkey, who had an average age of 4 years ( 8 months to 12 years) and those of the Necker children sick team in France, who in a series of 19 children collected in 15 years of experience observed that children Were an average of 3 years ( 3 months to 10 years) [12]. The sex ratio was balanced in our series. It was 1.1 with a slight female predominance (52\%). Our results differ from those of By Omer Cakir et al. [11] with a male predominance (56\%). Similarly, other authors in Spain (Jaume Sadrista-Sauleda et al.) [13] found a male predominance of $63.2 \%$ (group I) and $64.3 \%$ (group II) in their two study groups.

\subsection{Clinic}

Typically, the diagnosis is clinical and electrical, based on at least two of the following four criteria: chest pain, pericardial friction, compatible ECG abnormalities (ST segment diffuse elevation, PR segment depression), echocardiogram pericardial effusion [14].

In about two thirds of the cases, chest signs inaugurated the clinical picture (dyspnea in 27 cases, thoracic pain in 20 cases). This was the observation of the authors of the Parisian team [12]. Dyspnea is present in all cases to varying degrees. In our African countries and particularly in Côte d'Ivoire, dyspnea is not specific, as it is observed in other conditions such as acute community-acquired pneumonia. Community acute lung disease is the second leading cause of hospitalization in Côte d'Ivoire. It remains severe and lethal despite the advent of antibiotic therapy, and is often associated with HIV infection in 33\% of cases, which severely affects mortality [15].

Chest pain is most evocative when it is inspiratory and relieved at the anteflexion. It is the second reason for consultation (64\%), compared with $84.2 \%$ for BH Maiga [16], 53.8\% for Diallo [17], 94.6\% for Serme in Ouagadougou [18] At Roy's [19].

The fever, present only in $10 \%$ of the patients of our series, should no longer be considered a usual sign. In tropical Africa, its presence suggests malaria until 
proven otherwise, as malaria accounts for about $10 \%$ of ambulatory consultations and remains one of the leading causes of death for children under five years of age [20]. Thus the fever isolated or associated with dyspnea or chest pain explains the late diagnosis of pericarditis in our country because assimilated to pathologies such as malaria and acute pneumopathy. This explains in part that pericarditis was seen late.

Tachycardia is the dominant stethacoustic sign with $97 \%$.

Theoretically perceived in almost $75 \%$ of cases [21], the pericardial friction proves in practice of great specificity but of low sensitivity. In our study, it was only seen in $17 \%$ of patients. This is in line with the recent series [22]. The fugitive character of the friction, especially in the case of late management, may partly explain this discordance, but more importantly the abundance of the pericardial effusion (the pericardial leaflets can not be touched).

The rarely normal electrocardiogram makes it possible to evoke the diagnosis. The most frequently observed signs are micro-voltage and repolarization disorders, which are mainly limited to an isolated sus-ST. Early treatment prevents the evolution towards the other stages of Holzmann's chronological classification [2]. This elevation of the ST, usually found in 65 to $85 \%$ of cases [22], was noted in all our patients (100\%).

The chest radiograph standard in frontal incidence objective a cardiomegaly in all the patients of our series (100\%). The importance of standard radiography in face incidence in the positive diagnosis of pericarditis is very appreciable. Pericardial calcifications were not found during our study. Thus, it is necessary to ask before a pericarditis a profile shot where the pericardial calcifications are better recognized according to the literature [23].

\subsection{Etiologies}

\subsubsection{Tuberculous Pericarditis}

In our country, tuberculosis is the most frequent aetiology because of its endemicity character in Côte d'Ivoire. The diagnosis of tuberculous pericarditis is based on a set of epidemiological, clinical, biological and echo-cardiographic arguments. The exudative nature of the pericardial fluid and the fibrosis lesions associated with calcifications constituted presumptive arguments for the diagnosis of tuberculous pericarditis. However, in the absence of histological confirmation in our patients, good progress in tuberculosis treatment adds an argument in favor of tuberculosis. It was found in $52.4 \%$ of cases, which is probably underestimated. Indeed, the frequency of tuberculous etiology in our study is clearly higher than the others: $32 \%$ in Ouagadougou [18], 46\% in Kinshasa [24] and $48 \%$ in N'djamena [25]. Interestingly, $25 \%$ of children infected with the human immunodeficiency virus have a pericardial effusion [26]. Thus we have obtained the consent of parents for retrovirus research deleterious for patients and whose early diagnosis is paramount. The discovery of pericarditis in sub-Saharan Africa now requires mention of an underlying HIV infection. $50 \%$ to $70 \%$ of pericarditis is related to HIV in endemic areas [4] and the positive predictive value of tu- 
berculosis pericarditis is high: more than $90 \%$ of tuberculous pericarditis confirmed by pericardial biopsy was Associated with HIV in the Mather et al study [27].

\subsubsection{Rheumatic Pericarditis}

Rheumatoid arthritis (RAA) and its valvular sequelae, chronic rheumatic heart disease (CRC), affect mainly children, adolescents and young adults. Worldwide, their prevalence is estimated to be between 15.6 and 78 million cases, with 282,000 incidents and 250,000 deaths per year [28] [29]. Rare in developed countries, these diseases persist in developing countries, particularly in sub-Saharan Africa and Asia [30] [31]. They also persist in the pacific region [32] and in the indigenous populations of Australia [33].

Rarely isolated, it was integrated into the pancardites but left no sequelae, except sometimes with adhesive pericarditis or asymptomatic calcifications.

Rheumatic pericarditis occupies the second place in our series (14.3\%). Its diagnosis is easy if it falls within an obvious context of acute rheumatic fever. In our developing countries, the RAA is a public health problem with an incidence of 100 to 200/100,000 children; it also remains a cause of cardiovascular morbidity and mortality [34] [35]. Therapeutically, antibiotics were prescribed systematically in all cases for ten days. It was Penicillin $\mathrm{G}^{\circledR}$ at a rate of one million IU twice a day. Corticosteroids were also prescribed.

\subsubsection{Pericarditis with Common Germ}

It is now the most severe etiology after pericardial cancers, with mortality exceeding $35 \%$ (and $100 \%$ in the absence of treatment) [36] [37] [38]. Classically the triad "fever, presence of an infectious focus and tamponade" makes it possible to affirm suppurative pericarditis. But often the picture is much more torpid, dominated by fever, with few pericardial signs: so that one should propose the echocardiogram in the list of examinations to be practiced systematically in case of fever.

In the long term without a detectable cause, all the more so, of course, if one detects the slightest chest sign.

Bacterial pericarditis is relatively less important in Africa.

They seem to be the prerogative of children and young adults affected by them, which are still affected to a very high level of around 43\% in 1992 in Uganda according to D'ARBELA [39].

In this study, its frequency was $7.1 \%$. This relatively low frequency is partly explained by the fact that several patients are often subjected to antibiotic therapy in an empirical manner, hindering the demonstration of the pathogen.

Our results are relatively superior to those of SERME, whose work is $2.7 \%$ [18]. In Africa, according to ADEYEMO [40] and AGBOTON [41], septic pericarditis is mainly observed in patients from rural areas where hygiene is precarious.

An extrapericardial infectious localization (portal of entry or other septic me- 
tastasis) was found 11 times with diagnosis with major therapeutic implications (11.7\%). We insist on the interest of echocardiography in the positive diagnosis of these pericarditis which are often accompanied by more or less abundant effusion.

Pericardial puncture frequently reduces a purulent fluid of variable aspect according to the germ in question, which is in order of frequency, Staphylococcus aureus in one third of cases followed by pneumococcus in 19\% [40] [41].

The evolution of these septic pericarditis is still serious because it is dominated by the prognosis of septicemia, the precocity and efficacy of the antibiotic treatment associated with preventive corticosteroid therapy of pericardial constriction [40]. In spite of all the evolution will be commonly towards the pericardial constriction with or without cardiac tamponade in $30 \%$ of cases [41].

\subsubsection{Neoplastic Pericarditis}

There are two types of tumor, with a very different percentage: primary tumors [42] (rare, dominated by malignant mesothelioma) and pericardial metastases much more frequent [43] [44], often lost in a table of Generalization of the cancer but sometimes present a clinical originality (inaugural pericardial incidental attack or late complication of a cancer already treated but threatening and requiring a rescue gesture).

The major prognostic implication of neoplastic pericarditis fully justifies its screening. Cytological analysis of pericardial fluid found carcinomatous cells in 3 patients $(7.1 \%)$. The absence of a pericardial biopsy that can confirm the cancerous nature was one of the limitations in this study. Most authors found equivalent effects (7\%). This was our observation (7.1\%) and that of Lange et al. [21].

\subsubsection{Chronic Parietal Endocarditis}

This etiology was found in $11.9 \%$ of patients in our series.

Chronic parietal endocarditis (EPC) is the most common cardiac manifestation of eosinophil toxicity. This frequent disease in the intertropical regions would be markedly increased.

\subsubsection{Post-Mortem Syndrome}

A complication with frequency, up to $30 \%$, varies considerably with the surgical teams, it is clinically similar and probably due to its pathogenesis to Dressler's syndrome: acute pericarditis occurring during the convalescence of a cardiac procedure where the pericardium has been opened. There again relapses, increasing the discomfort of the patient and the duration of the hospitalization. The "surgical responsibility" would be rejected by an ingenious hypothesis: an immunological feature that makes them react to the mandatory myo-epicardial attritions of the intervention (a feature triggered by a latent virus causing cross-reactions of hypersensitivity). This painful and painful syndrome should not be confused with the postoperative asymptomatic pericardial effusion dis- 
covered by systematic echographic monitoring and which regresses in a few weeks.

Post-operative syndrome is similar to Dressler's syndrome and cardiac trauma. It is of uncertain etiology [45]. This syndrome is characterized by chest pain, fever, pericardial friction, pleural effusion, malaise and anorexia [46]. Its incidence is close to $30 \%$, but may be lower in children less than 2 years of age [47]. We observed two cases (4.8\%) in our series. Our results are significantly lower than those of the Lausanne team in Switzerland (42.2\%) [48].

\subsection{Evolution and Complications}

The development of pericarditis is burdened with heavy mortality, or $10 \%$ of cases in our series. Indeed, the overall mortality of pericarditis of all forms as reported is variable according to the authors. In a previous study, it represented $3.57 \%$ of deaths in Abidjan [49] and 6.06\% in Niamey [50]. Finally, this study allowed us to observe that the mortality during acute pericarditis seems to be favored by the appearance of certain evolutionary complications, themselves favored more often by the etiology of acute pericarditis.

In this study, the most common complication was adiastolia (97\%) due to delayed consultation and diagnosis in our developing countries.

Thus the passage to chronicity complicates essentially pericarditis seen late, 7 cases in our series (16\%).

The prevalence of tamponade varies from $19 \%$ to $22 \%$ for older series to $5 \%$ for the most recent [51] [52]. Beyond the figures, the occurrence of tamponade appears mostly a function of the etiology of pericarditis. Tuberculous, purulent and neoplastic forms are complicated by tamponade in nearly two-thirds of cases [53]. The occurrence of such a complication must therefore lead to an exhaustive and sometimes invasive etiological assessment.

\section{Conclusion}

Fluid pericarditis in children is a severe condition that is clearly on the rise today, especially in immunocompromised patients. The etiological diagnosis is subject to multiple difficulties due to a wide variety of causes. Tuberculosis is still prevalent in our country, hence the importance of preventing this disease. Unfortunately, the diagnosis of pericardial tuberculosis has often been carried without bacteriological and/or histological evidence on a bundle of anamnestic, clinical, paraclinic, therapeutic and evolutionary arguments. Optimal management of fluid pericarditis in children is the best guarantee to avoid short-term tamponade and in the medium term constriction.

\section{Acknowledgements}

All the authors are thankful for providing the necessary facilities for the preparation the manuscript. Special thanks are due to the Institute of cardiology of Abidjan (ICA) and to the Department of Pediatric of Hospital and academic of 
Treichville (HUSH); the source(s) of funding for all authors.

\section{Consent}

Research was made according to the principles of the Declaration of Helsinki (https://web.archive.org/web/20071027224123/http://www.wma.net/e/policy/pdf /17c.pdf).

The agreement of the department head, the anonymity and the destruction of the cards of investigation after their exploitation were respected.

\section{Contribution of the Authors}

All the authors contributed intellectually to the preparation and the revision of the manuscript.

They all approved it before its tender.

\section{Financial Support and Sponsorship}

Nil.

\section{Competing Interests}

The authors declare that they have no competing interests.

\section{References}

[1] World Health Organization (2008) Ten Highlights in Health Statistics. In: WHO, Ed., World Health Statistics, WHO, Geneva, 30-31.

[2] Troughton, R.W., Asher, C.R. and Klein, A.L. (2004) Pericarditis. Lancet, 363, 717-727.

[3] Malu, K., Longo-Mbenza, B., Lurhuma, Z. and Odio, W. (1988) Pericarditis and Acquired Immunodeficiency Syndrome. Archives des Maladies du Coeur et des Vaisseaux, 81, 207-211.

[4] Niakara, A., Drabo, Y.J., Kambire, Y., Nebie, L.V.A., Kabore, N.J.P. and Simon, F. (2002) Cardiovascular Disorders and HIV Infection. Bulletin De La Societe De Pathologie Exotique, 95, 23-26.

[5] De Castro, S., Migliau, G., Silvestri, A., et al. (1992) Heart Involvement in AIDS: A Prospective Study during Various Stages of the Disaese. European Heart Journal, 13, 1452-1459. https://doi.org/10.1093/oxfordjournals.eurheartj.a060085

[6] Heindrich, P.A., Eisenberg, M.J., Kee, L.L., et al. (1995) Pericardial Effusion in AIDS: Incidence and Survival. Circulation, 29, 3229-3234.

[7] Barbaro, G.M.D. (2001) Cardiovascular Manifestations of HIV Infection. Journal of the Royal Society of Medicine, 94, 384-390.

[8] Wanchu, A., Dong, Y., Sethi, S., Myneedu, V.P. and Nadas, A. (2008) Biomarkers for Clinical and Incipient Tuberculosis: Performance in a TB Endemic Country. PLoS ONE, 3, e2071. https://doi.org/10.1371/journal.pone.0002071

[9] Benchekroun, T.S., Jorio-Benkhraba, M. and El Malki-Tazi, A. (1998) Acute and Subacute Pericarditis in Children: 10 Years of Experience. Maghrebian Review of Pediatrics, volume, 185-192.

[10] Hmami, S., Atmani, A., Bouharrou, M., Hida, K., Khatalla, Y., Abouabdellah, I., 
Harandou Labib, M. (2010) Acute Pericarditis in Children: About 34 Cases. Archives of Pediatrics, volume, 395.

[11] Cakir, O., Gurkan, F., Balci, A.E., Eren, N. and Dikici, B. (2002) Diyarbakır, Turkey. Purulent Pericarditis in Childhood: Ten Years of Experience. Journal of Pediatric Surgery, 8, 1404-1408. https://doi.org/10.1053/jpsu.2002.35401

[12] Thébaud, B., Sidi, D. and Kachaner, J. (1996) The Purulent Pericarditis of the Child: 15 Years of Experience. Archives of Pediatrics, 3, 1084-1090.

[13] Sagrista-Sauleda, J., Aarrabes, J.A., Permanyer-Miralda, G. and Jordi, S. (1993) Purulent Pericarditis: Review of a 20-Year Experience in a General Hospital. Journal of the American College of Cardiology, 22, 1661-1665. https://doi.org/10.1016/0735-1097(93)90592-O

[14] Imazio, M., Spodick, D.H., Brucato, A., Trinchero, R. and Adler, Y. (2010) Controversial Issues in the Management of Pericardial Diseases. Circulation, 121, 916-928. https://doi.org/10.1161/CIRCULATIONAHA.108.844753

[15] Horo, K., Koffi, N., Kouassi, B., N'gom, S., Kenmogne, K., Ahui, B.J.M. and Aka-Danguy, E. (2004) Factors of Death from Acute Community-Acquired Pneumonia in African Settings in Abidjan. Rev Pneumol Too, 1, 10-13.

[16] Maiga B.H. (2005) Epidemioclinic Study of Acute Pericarditis in the Cardiology Department of HNPG: About 76 Cases. Medical Thesis, Bamako, 2005, 05-M-101.

[17] Diallo, S. (1998) Retrospective Study of Pericarditis at the G National Hospital: 91 Cases. Thesis Med Bamako, 1998, 28.

[18] Serme, D., Lengani, A. and Ouandaogo, J. (1991) Acute Pericarditis of Adults in Ouagadougou: Clinical and Etiological Aspects of 37 Cases. Cartoon Network, 17, 141-147.

[19] Roy, J.C., Gonel, V., Condot, J.M., et al. (1981) Adult Pericarditis in Abidjan, Study of 100 Observations. Sem hop, 57, 978-983.

[20] Anonyme (1994) Antimalarial Drug Policies: Data Requirements, Treatement of Uncomplicated Malaria and Management of Malaria in Pregnancy. WHO/MAL, Geneva.

[21] Lange, R.A. and Hillis, L.D. (2004) Clinical Practice. Acute Pericarditis. The New England Journal of Medicine, 351, 2195-2202.

[22] Imazio, M., Demichelis, B., Cecchi, E., et al. (2003) Cardiac Troponin I in Acute Pericarditis. Journal of the American College of Cardiology, 42, 2144-2148. https://doi.org/10.1016/j.jacc.2003.02.001

[23] Fouet, X.A. (1999) Cardiology 1st, 2nd and 3rd Cycle of General Medicine (Preparation for an Internship). University press of Lyon.

[24] Kintaki, V. (1981) Tuberculous Pericarditis in Zaire about 30 Cases Observed at University Clinics in Kinshasa from 1957 to 1976. South African Medical Journal, 28, 7-9.

[25] Mouanodji, M.B. (1996) Pericarditis in N’Djamena (Chad), Epidemiological, Symptomatological, Etiological and Evolutionary Study. Card Too, 22, 17-20.

[26] Starc, T.J., Lipshultz, S.E., Kaplan, S., et al. (1999) Cardiac Complications in Children Infected with the Human Immunodeficiency Virus. Pediatric Lung Complications and Cardiac Vertical Transmission of HIV Infection Study Group (T2C2 HIV), National Heart, Lung, and Blood Institute. Pediatrics, 104, E14. https://doi.org/10.1542/peds.104.2.e14

[27] Mather, D. and Harries, A.D. (1997) Tuberculous Pericardial Effusion: A Prospective Clinical Study in a Low-Resource Setting-Blantyre. Malawi. International Journal of 
Tuberculosis and Lung Disease, 1, 358-364.

[28] Marijon, E., Mirabel, M., Celermajer, D.S. and Jouven, X. (2012) Rheumatic Heart Disease. Lancet, 379, 953-964. https://doi.org/10.1016/S0140-6736(11)61171-9

[29] Seckeler, M.D. and Hoke, T.R. (2011) The Worldwide Epidemiology of Acute Rheumatic Fever and Rheumatic Heart Disease. Journal of Clinical Epidemiology, 3, 67-84. https://doi.org/10.2147/CLEP.S12977

[30] Nsubuga, P., White, M., Fontaine, R. and Simone, P. (2008) Training Programmes for Field Epidemiology. Lancet, 371, 630-631. https://doi.org/10.1016/S0140-6736(08)60281-0

[31] Moren, A., Drucker, J. and van Loock, R. (1998) Epiet: Training in Epidemiology of Intervention in Europe. Epidemiologic Reviews, 46, 533-540.

[32] Fourcade, L. (2008) Cardiopathies rhumatismales dans les pays en développement: où en sommes nous? (Rheumatic heart diseases in the developing countries: where are we?) Med. Trop., 68, 660.

[33] Good, A. (2013) Laboratory Surveillance of Suspected Community-Acquired Methicillin Resistant Staphylococcus Aureus (CA-mRSA) in Seychelles, 2010-2012. 1st International Forum on Health and Response in Island Territories. 11-13 June. Saint-Denis, Reunion Island. http://www.forum-veille-sanitaire-oi.org

[34] Barsaoui, S. and Oubich, F. (2005) Rheumatic Fever in Children. Pediatrics, 2, 243-255.

[35] Olivier, C., Portier, H., Cohen, R., Schilmmer, B., Boucot, I. and Peyramond, D. (1999) Results of a National Survey of Rheumatoid Arthritis (1995-1997). Pediatrics, 6, 375-378.

[36] Falcon-Eicher, S., Eicher, J.C., Collet, E., et al. (1995) Pericarditis Purulent during Dermatomyositis. Annales de Cardiologie et d Angéiologie, 44, 21-24.

[37] Guerot, E., Assayag, P., Morgan, C., et al. (1992) Pericardial Manifestations of Toxoplasmosis. Archives des Maladies du Coeur et des Vaisseaux, 85, 109-111.

[38] Habis, M. (1995) Purulent Pericarditis of the Adult. Journal of Cardiology, 79, 8-12.

[39] D’Arbela, P.G., Patel, A.K., Grigg, G.L. and Somers, K. (1972) Pericarditis, with Particular Emphasis on Pyogenic Pericarditis: A Uganda Experience. East African Medical Journal, 49, 803-815.

[40] Adeyemo, A.O, Andy, J.J, Joiner, R.T. and Odesanne, W.O. (1985) Purulent Pericarditis in Nigeria: À Study of 36 Consecutive Cases. Cardiology, 11, 7-13.

[41] Agboton, H. (1984) Acute pericarditis in West Africa. Cardiology, 17, 17-23.

[42] Loire, R. and Tabib, A. (1994) The Malignant Mesothelioma of the Pericardium. Anatomo-Clinical Study of 10 Cases. Archives Des Maladies Du Coeur Et Des Vaisseaux, 87, 255-262.

[43] Kralstein, J. and Frishman, W. (1987) Malignant Pericardial Diseases: Diagnosis and Treatment. American Heart Journal, 113, 785-790. https://doi.org/10.1016/0002-8703(87)90720-4

[44] Loire, R. and Hellal, H. (1993) Péricardites Néoplasiques. Étude par Thoracotomie et Biopsie Dans 80 Cas. La Presse Médicale, 22, 244-248.

[45] Jarrod, D. and Knudson, M.D. (2011) Diseases of the Pericardium. Congenital Heart Disease, 6, 504-513.

[46] Clapp, S.K., Garson Jr., A., Gutgesell, H.P., Cooley, D.A. and McNamara, D.G. (1980) Post-Operative Pericardial Effusion and Its Relationship with Postpericardiotomy Syndrome. Pediatrics, 66, 585-588. 
[47] Engle, M.A., McCabe, J.C., Ebert, P.A. and Zabriskie, J. (1974) The Postpericardiotomy Antiheart Syndrome. Circulation, 49, 401-406. https://doi.org/10.1161/01.CIR.49.3.401

[48] Niclauss, L. and von Segesser, L.K. (2011) Pericardial Effusion-Percutaneous Therapeutic Options versus Open Surgery. Forum Medicine Switzerland, 11, 187-191.

[49] Odi Assamoi, M., Thomas, J.J., Lebras, M. (1975) Purulent Pericarditis in Abidjan (About 21 Cases). Cardiology, 1, 15-28.

[50] Cenac, A., Mounio, O.M., Develoux, M., Soumana, I., Lamothe, F., Gaultier, Y. and Kanarzewski, R. (1985) Adult Cardiopathies in Niamey (Niger). A Prospective Epidemiological Survey of 162 Observations. Cardiology, 43, 126-133.

[51] Imazio, M., Demichelis, B., Parrini, I., et al. (2004) Day-Hospital Treatment of Acute Pericarditis: A Management Program for Outpatient Therapy. Journal of the American College of Cardiology, 43, 1042-1046. https://doi.org/10.1016/j.jacc.2003.09.055

[52] Sudano, I., Spieker, L.E., Noll, G., Corti, R., Weber, R. and Lüscher, T.F. (2006) Cardiovascular Disease in HIV Infection. American Heart Journal, 151, 1147-1155. https://doi.org/10.1016/j.ahj.2005.07.030

[53] Permanyer-Miralda, G. (2004) Acute Pericardial Disease: Approach to the Aetiologic Diagnosis. Heart, 90, 252-254. https://doi.org/10.1136/hrt.2003.024802

Submit or recommend next manuscript to SCIRP and we will provide best service for you:

Accepting pre-submission inquiries through Email, Facebook, LinkedIn, Twitter, etc. A wide selection of journals (inclusive of 9 subjects, more than 200 journals)

Providing 24-hour high-quality service

User-friendly online submission system

Fair and swift peer-review system

Efficient typesetting and proofreading procedure

Display of the result of downloads and visits, as well as the number of cited articles

Maximum dissemination of your research work

Submit your manuscript at: http://papersubmission.scirp.org/

Or contact ojped@scirp.org 